\title{
RISET APLIKASI KESELAMATAN KEBAKARAN DI KAPAL
}

\author{
Zulfaidah Ariany \\ Program Studi Diploma III Teknik Perkapalan \\ Fakultas Teknik Universitas Diponegoro
}

\begin{abstract}
Zulfaidah Ariany, in this paper explain that fire ship at sea is a dangerous thing, both on the ship itself or on its passengers. Crew boat had put out the fire without the help of other collateral. Without a good extinguishing system will certainly result in damage to the ship and would endanger the safety of the soul crew and passenger ships.

Ship fire safety research conducted by various parties including government organizations and non governmental organizations and academic institutions related to fire safety aspects of shipping and ship.I

The need for revision of regulations that have been enacted sail for this through the provision of research. Research conducted to gain understanding of the dangers that may occur on the ship, and a good method for controlling and extinguishing the fire. Research that was conducted earlier used as a basis in research notes or to come.
\end{abstract}

Keywords : ship fire, fire safety

\section{PENDAHULUAN}

Kebakaran kapal di laut merupakan hal yang membahayakan, baik pada kapal itu sendiri atau pada penumpangnya. Crew kapal harus memadamkan api tanpa adanya jaminan bantuan dari pihak lain. Tanpa adanya sistem pemadaman yang baik tentu akan mengakibatkan kerusakan kapal serta akan membahayakan keselamatan jiwa crew serta penumpang kapal.

Sebuah survey mengenai kecelakaan kapal mengklasifikasikan penyebab kecelakaan kapal menjadi beberapa kategori berikut ini: kandas, kebakaran; meski masih ada penyebab-penyebab yang lainnya yang dianggap juga bisa membahayakan keselamatan kapal serta penumpangnya. Survey tersebut menyebutkan bahwa hampir 25\% keruguian akibat kecelakaan kapal disebabkan oleh kebakaran dan lebih dari 50 \% korban jiwa pada kecelakaan kapal disebabkan oleh kebakaran.

Kebakaran di kapal merupakan hal yang sangat membahayakan yang bisa menyebabkan kerugian yang sangat besar, baik terhadap kapal atau muatannya. Serta akan membahayakan jiwa penumpang dan crew kapal. Pada jaman ketika kapal masih terbuat dari kayu, lampu yang digunakan untuk penerangan kapal adalah lampu minyak atau parafin. Pada saat itu kebakaran sangat sering terjadi sebagai akibat dari gerakan kapal yang menyebabkan lampu minyak pecah atau jatuh dan mengenai badan kapal yang terbuat dari kayu. Meski pada saat ini lampu minyak dilarang penggunaanya, resiko kebakaran masih tetap ada.

Kandasnya kapal niaga juga bisa menyebabkan kebakaran dan ledakan kapal. Seperti yang terjadi pada kapal tanker Torrey Canyon yang kandas dan kemudian mengalami kebakaran dan ledakan pada tahun 1967. Mungkin saja produk petrolium merupakan muatan berbahaya beresiko tinggi terhadap kebakaran saat bongkar muatnya, namun muatan lainnya juga bisa menyebabkan terjadinya kebakaran saat terjadi kecelakaan kapal. Muatan tersebut misalnya batubara, muatan kering, biji-bijian, yang kelihatannya tidak membahayakan, namun bisa menyebabkan kebakaran kapal.

Penyelidikan kecelakaan menunjukkan bahwa kebakaran yang fatal bukan hanya terjadi pada kapal yang memuat bahan-bahan berbahaya, tetapi juga terhadap kapal yang memuat bahanbahan yang tergolong tidak berbahaya, seperti gula, kacang-kacangan, cotton, dan yang lainnya. Bahanbahan tersebut dapat dengan mudah terbakar jika lingkungan disekitarnya mendukung terjadinya kebakaran, seperti suhu yang tinggi serta jumlah oksigen yang ada. Jikas terjadi lebakaran akan sulit untuk mematikan bahan yang mudah terbakar ini, terlebih jika oksigen yang ada di sekitarnya cukup banyak karena api akan mudah sekali menyebar.

\section{KESELAMATAN KEBAKARAN KAPAL Organisasi Pemerintahan}

Penelitian dalam hal kebakaran kapal sangat penting untuk mencegah terjadinya kebakaran kapal serta meminimalisasi kerusakan serta korban jiwa akibat kebakaran kapal. Penelitian tentang kebakaran kapal membutuhkan ahli-ahli dari berbagai pihak yang terkait, misalnya fire engineering, safety engineering, communication engineering, dan ahli-ahli bidang yang lain. Penelitian yang telah dilakukan selama ini dilakukan oleh berbagai pihak, misalnya pihak pemerintahan, swasta, organisasi non pemerintah, 
akademisi, ataupun gabungan antara badan-badan tersebut.

Badan pemerintahan yang melakukan penelitian tersebut misalnya National Transporatation Safety Board (NTSB), Maritime Safety Quensland, Australia Transport Safety Bureau, Institute for Research in Construction National Research Council Canada dan lain-lain. Badan-badan tersebut mengadakan penelitian diawali jika terjadi kecelakaan kapal, setelah terjadinya kecelakaan kapal, badan pemerintahan tersebut akan mengadakan investigasi yang bertujuan untuk mengetahui penyebab terjadinya kebakaran kapal dan kemudian akan memberikan rekomendasi pada pihak terkait untuk pencegahan terjadinya kebakaran kapal yang lainnya.

Seperti yang dilakukan oleh NTSB, badan ini menginfestigasi kecelakaan kapal yang terjadi di Amerika Serikat. Salah satu kecelakaan kapal yang diselidiki adalah kecelakaan kebakaran kapal penumpang Ecstacy Miami, yang terjadi di Florida pada tahun 1998. Investigasi dilakukan untuk mengetahui penyebab kebakaran kapal dan setelah mengetahui penyebab terjadinya NTSB memberikan rekomendasi pada beberapa pihak untuk mencegah terulangnya kebakaran kapal, seperti pada industri pelayaran, galangan, penjaga pantai, atau biro klasifikasi.

Dalam laporan kepada publik NTSB mendiskusikan hal-hal berikut ini: kelayakan sistem pemadam kebakaran di kapal tersebut, manajemen keselamatan, serta desai system engineering. Sebagai hasil penelitiannya NTSB membuat rekomendasi kepada U.S. Coast Guard, American Classic Voyages, Carnival Corporation, Inc., Carnival Cruise Lines, Crystal Cruises, Disney Cruise Line, Norwegian Cruise Line, Orient Lines, P\&O Princess Cruises International, Ltd., Radisson Seven Seas Cruises, Regal Cruises, Renaissance Cruises, Inc., Royal Olympic Cruises, Royal Caribbean Cruises, Ltd., and Silversea Cruises, Ltd., ABB, Inc., and the International Association of Classification Societies. Rekomendasi ini diberikan dengan tujuan agar kecelakaan karena kebakaran tidak terulang lagi.

NTSB merupakan agen federal independan yang melakukan penyelidikan dalam hal keselamatan penerbangan, perkereta-apian, jalan raya, kelautan dan materia-material berbahaya. Badan ini didirikan pada tahun 1967, dibawah pengawasan Konggres melalui Independent Safety Board Act untuk menyelidiki kecelakaan transportasi, menentukan penyebab-penyebabnya, mengeluarkan rekomendasi-rekomendasi, mempelajari keselamatan transportasi, dan mengevaluasi keefektifan agen-agen pemerintahan yang terkait dengan keselamatan transportasi.
NTSB kemudian mengeluarkan laporan kepada publik.

Selain menyelidiki kecelakaan kapal badan pemerintahan ini juga mengadakan riset pencegahan terjadinya kebakaran, misalnya riset tentang bahan-bahan berbahaya yang bisa menyebabkan kebakaran kapal. Misalnya riset yang dilakukan oleh Maritime Safety Quensland. Badan ini mangadakan riset tentang pirogen sebagai bahan pemadam api. Meski pirogen disetujui penggunaannya oleh United Kingdom's Marine and Coastguard Agency serta Bureau Veritas. Terdapat beberapa kejadian dimana discharge dari sistem ini disertai oleh peningkatan tekanan pada ruangan yang dipadamkan yang bisa menyebabkan masalah yang lainnya. Juga terdapat kecelakaan akibat keluarnya aerosol ini akibat gelombang dari mobile phone atau dari gelombang radio VHF. Gelombang ini juga bisa menyebabkan penyalaan pada generator pirogen.

Dengan adanya fakta tersebut Maritime Safety Quensland kemudian memberikan rekomendasi tentang penggunaan pirogen ini untuk mencegah terjadinya kecelakaan yang disebabkan oleh pirogen. Penelitian tentang pirogen ini di publikasikan kepada umum melalui buletin yang diterbitkan oleh Maritime Safety Quensland.

\section{Organisasi Non Pemerintah}

Pihak yang lain yang juga ikut serta dalam penelitian kebakaran kapal adalah organisasi non pemerintahan. Pihak pihak tersebut antara lain, Maritime Safety Comittee dan International Organization for Standardization.

Maritime Safety Comittee adalah sebuah komite yang terdiri atas beberapa negara di Eropa, yaitu Perancis, Jerman, Belanda, dan Swedia. Komite ini mengadakan penelitian tentang keselamatan kapal. Salah satu penelitian yang dilakukan adalah SURSHIP-Survivability of Ship. Penelitian ini dimulai pada tahun 2006 dan direncanakan akan diadakan sampai tahun 2009. Tujuan penelitian ini adalah untuk peningkatan keselamatan kapal melalui desainan kapal yang bisa meningkat kemampuan survive saat terjadi kecelakaan kapal.

Beberapa negara ikut dalam penelitian ini untuk mengembangkan metode dan teknik pembangunan kapal, peraturan-peraturan peningkatan keselamatan kapal, yang tentunya akan meningkatkan keselamatan kapal serta kemampuan prediksi resiko kecelakaan kapal.

Negara-negara yang ada dalam komite ini percaya bahwa akan lebih mudah untuk mengadakan penelitian jika diadakan joint research oleh beberapa negara, dan usaha-usaha pengembangan akan jauh lebih mudah. Selain 
alasan tersebut, alasan dalam bidang elonomi juga menjadi pertimbangan utama. Penelitian yang dilakukan antara lain kemampuan ketahanan kapal pada saat kecelakaan.

Kerjasama ini dipandang akan menguatkan industri maritim di Eropa serta akan meningkatkan pengetahuan tentang pembangunan kapal yang akan memberikan keuntungan kepada pemilik kapal, galangan kapal, pemerintahan, serta akan memberikan kontribusi kepada International Maritime Organization.(IMO).

Fokus penting dalam SURSHIP adalah penelitian dan pengembangan yang terkait dengan kemampuan kapal untuk tetap mengapung pada posisi yang semestinya, baik pada saat terjadi kecelakaan yang disebabkan oleh tabrakan, kandas, atau kebakaran. Ide mendasar untuk desain ini adalah untuk keselamatan jiwa crew serta penumpang kapal saat terjadi kecelakaan kapal. Bagaimana evakuasi penumpang dapat dilaksanakan dengan baik agar korban jiwa seminimal mungkin, adalah dasar penelitian ini. Sehingga penelitian dilaksanakan terkait dengan konstruksi kapal yang bisa memperkecil korban jiwa saat terjadi kecelakaan kapal.

\section{Institusi Akademik}

Institusi Akademik juga merupakan salah satu pelaku riset dalam bidang kebakaran kapal. Pelajar atau staf pengajar mengadakan penelitian tentang berbagai hal, termasuk dalam bidang kebakaran di kapal.

Salah satu institusi internasional yang melakukan penelitian dalam bidang kebakaran kapal adalah University of ULSTER. Pada universitas ini terdapat departemen Fire Engineering. Yang memiliki badan penelitian tentang kebakaran di prasarana umum, termasuk kebakaran di atas kapal. Badan penelitian tersebut adalah Institute of Fire Safety Engineering Research and Technology (FireSERT), sebuah kelompok peneliti internasional yang mengadakan penelitian dalam hal kebakaran dengan menggunakan metode penelitian serta fasilitas yang terkini.

Penelitian dilakukan dalam hal, fire dynamics, structural fire engineering, human behaviour pada saat terjadi kebakaran dan fire modelling. Penelitian dilakukan oleh staf pengajar, bahkan hampiur semua staf pengajar melakukan penelitian. Selain staf pengajar mahasiswa juga bisa menggunakan fasilitas yang ada pada badan penelitian untuk mengadakan risetnya yang terkait dengan proses pembelajaran serta proyek penelitian yang lainnya.
Badan penelitian ini juga bekerja sebagai konsultan untuk fire safety engineering design serta fire safety engineering pada bidang offshore oil exploration, baik pada proses produksi atau penyimpanan.

\section{KESIMPULAN}

Keberadaan peraturan-peraturan intenasional yang terkait dengan keselamatan kebakaran kapal telah ada sejak dahulu, namun dengan perkembangan teknologi yang ada saat ini tentu peraturan tersebut perlu untuk direvisi. Revisi yang dilakukan bisa terjadi melalui pengadaan riset. Riset dilaksanakan untuk memperoleh pengertian terhadap bahaya yang mungkin terjadi di atas kapal, dan metode yang baik untuk pengendalian serta pemadaman api. Riset-riset yang telah dilaksanakan terdahulu digunakan sebagai catatan atau dasar dalam riset yang akan datang.

\section{DAFTAR PUSTAKA}

1. Australian government, Australian Transport Safety Bureau, Fire Safety Analysis of the Polar Icebreaker Replacement Design. Volume 3. Part 2

2. International Organization for Standardization (ISO), TC8 (Ship and Marine Technology) SC1 (Life-saving appliances and Fire protection)

3. 2007, Maritime Safety Committee, SURSHIP PROGRAM.

4. National Trasportational Safety Board, 1998, Marine Accident Report, Washington DC.

5. Marine Accident Investigation Branch, Summary of Investigations No 2/94, Southtamton

6. Online Prospectus University of Ulster Postgraduate Diploma_MSc, Fire Safety Engineering.

7. Quensland Government- Maritime Safety Quensland, Marine Information Bulletin, 2007, the use of pyrogen aerosol fire suppressant.

8. S. Mendiola, J.J. Achútegui, and M.A. De la Rosa,Fire Ranks Second in Maritime Casualties, Firenet (maritime), International Maritime Fire and Rescue Information, http://www.fire.org.uk/marine/papers/marinec asu.htm

9. 2008, Materi diskusi kuliah Manajemen Resiko dan Keselamatan Kapal, PPS-ITS, Surabaya. 
